\title{
DERECHOS Y LIBERTAD RELIGIOSOS Y LOS PUEBLOS INDÍGENAS FRENTE AL ESTADO MEXICANO
}

\author{
Artemia Fabre Zarandona
}

DiÁlogo y Movimiento, A. C.

TEPOZTLÁN, MORELOS

\begin{abstract}
RESUMEN
Este documento ${ }^{\mathrm{i}}$ pretende mostrar una problemática macrosocial al considerar la construcción de derechos humanos religiosos y de los pueblos indígenas en los ámbitos internacional y nacional, y cómo son o no retomados por las instancias nacionales no solo para la solución de conflictos religiosos sino también para garantizar los derechos humanos religiosos de los pueblos indígenas. Desde esta perspectiva interesa también, a la luz de los conflictos religiosos, observar cómo son ejercidos los derechos políticos y sociales por los indígenas y si los operadores de la justicia los toman en cuenta.
\end{abstract}

Palabras clave: Derechos religiosos, derechos de los pueblos indígenas, acceso a la justicia, conflictos, garantía de derechos.

\footnotetext{
${ }^{\mathrm{i}}$ El presente artículo, en una versión preliminar, fue presentado como ponencia en la Conferencia Internacional de RELAJU, México, en la Mesa 2.3 Constitucionalismo multicultural y derechos indígenas, coordinada por Raquel Irigoyen (Perú) y Morita Carrasco (Argentina); lugar y fecha: Oaxtepec, Morelos, de 16 a 20 de octubre de 2006. Para mayor profundidad sobre el tema que se aborda aquí puede consultarse mi tesis doctoral, realizada en Ciencias Antropológicas en la Universidad Autónoma Metropolitana-Iztapalapa (Fabre 2005).
} 


\begin{abstract}
This document ${ }^{\mathrm{ii}}$ aims to demonstrate a set of macrosocial problems regarding the construction of religious human rights and the human rights of indigenous peoples in the international and national spheres, and how they are or are not considered by national authorities, not only in resolving religious disputes, but also protecting the religious human rights of indigenous peoples. From this perspective, and in light of ongoing religious conflicts, the document also looks at how political and social rights are exercised by indigenous peoples, and whether said rights are taken into account by the administrators of justice.
\end{abstract}

Key words: Religious rights, indigenous rights, access to justice, conflicts, protection of rights.

\footnotetext{
ii A preliminary version of this article was presented at the International Conference of RELAJU, México in Table 2.3 Multicultural Constitutionalism and Indigenous Rights, coordinated by Raquel Irigoyen (Perú) and Morita Carrasco(Argentina), held in Oaxtepec, Morelos on 16-20 October 2006. For more information on the topic addressed here, consult the author's Doctoral Thesis in Antropological Sciences at the Universidad Autónoma Metropolitana-Iztapalapa (Fabre 2005).
} 


\section{INTRODUCCIÓN}

Considero que este aporte puede contribuir a la reflexión y el análisis sobre el lugar y el papel de los pueblos indígenas en el sentido del reconocimiento jurídico de sus derechos políticos y sociales, tal como están consignados en nuestra Constitución; también en que estos derechos sean ejercidos por los indígenas y los reconozcan o no los no indígenas, además, si son o no evidenciados por los operadores de la justicia en las controversias legales, en este caso, en los conflictos religiosos.

El propósito es presentar una problemática general sobre la construcción de los derechos humanos religiosos en el ámbito internacional y nacional para poder abordar conflictos religiosos, con especial interés en México, tomando en cuenta aquellos conflictos donde intervienen los pueblos indígenas.

Cabe resaltar que este artículo no trata casos concretos, presenta justamente una problemática y una mirada que nos permite acercarnos desde el ámbito macrosocial a los casos en nuestro país. Desarrollo este tema con mayor profundidad en mi tesis doctoral, donde expongo ejemplos de Oaxaca y la experiencia de trabajo de campo en otros estados (Fabre 2005).

Los conflictos religiosos conforman una compleja red de tensiones sociales y establecen una zona de difícil resolución jurídica en las controversias legales, debido tanto al mismo fenómeno religioso como a la falta de regulación clara en dicha materia; esta situación se presenta aun más compleja en las zonas indígenas por la ausencia de reconocimiento de facto de sus sistemas normativos y de las resoluciones que los indígenas toman, lo cual inmediatamente violenta el orden constitucional.

La reflexión sobre derechos religiosos y pueblos indígenas se vuelve parte de una agenda pendiente para contribuir a visibilizar la necesidad de un pluralismo jurídico, así como la 
retórica de un Estado pluricultural. La trayectoria del Estado mexicano y de la sociedad en general se ha definido por relaciones de poder claramente asimétricas hacia los pueblos indígenas, en las cuales la no visibilización de los pueblos indígenas o la minorización de los mismos ha sido una constante. ${ }^{1}$

Por lo anterior, interesa conocer cuáles son los lineamientos que han guiado la construcción de los derechos humanos religiosos y si estos incluyen o no a los pueblos colonizados. Desde la presente óptica se dan a conocer dos ejes que nos permiten observar 1) si hay referencias sobre las propias expresiones religiosas de los pueblos indígenas, y 2) si continúan prevaleciendo los esquemas que promueven la evangelización desde una perspectiva que da por sentado el derecho a misionar y evangelizar a esos pueblos como resultado de toda una historia que los ha construido como una otredad diferente e inferior.

Así el reto que se presenta es la construcción de ese «otro» no como inferior y sí como alguien a quien se puede dejar en paz $^{2}$ para que decida por sí mismo; también la observación de las relaciones económicas, políticas y sociales que han configurado la visión que se tiene actualmente del otro y cómo a su vez se asume bajo esta perspectiva, a pesar de los movimientos sociales ocurridos desde dentro de las comunidades indígenas para transformar esa mirada negativa y tratar de modificar el lugar al cual han sido relegados en la política nacional.

La antropología en general, y en el caso que nos ocupa la antropología jurídica, están llamadas hoy a tener una intervención contundente en asuntos nacionales, debido en parte a los procesos de democratización de la sociedad que nos impele, como comunidad académica, a tomar un lugar activo en los quehaceres del país. La antropología jurídica juega un papel importante en la generación de conocimiento que contribuye a una inserción jurídica y social más equitativa de sectores que requieren ser escuchados e integrados de manera constructiva y eficiente en la sociedad, como son los pueblos indígenas. 
La intervención académica de nuestra disciplina en el ámbito jurídico ya es parte de una agenda contemporánea que nos obliga a reflexionar desde el ámbito macrosocial con el fin de establecer una apertura y acciones locales que no solo contribuyan a crear marcos diversos de comprensión sino que de igual manera permitan crear propuestas legislativas edificantes y ampliar nuestro horizonte cultural y social hacia una sociedad plural de hecho.

Este trabajo es un aporte a la reflexión sobre el lugar jurídico que ocupan los pueblos indígenas y sobre los derechos religiosos ${ }^{3}$ en México.

\section{LOS PUEBLOS INDÍGENAS Y LA SOCIEDAD}

La historia de los pueblos indígenas en nuestro país se ha caracterizado por la dominación y la sujeción primero durante la Colonia, para posteriormente el Estado mexicano excluir a los indios jurídica y socialmente. Desde la primera Constitución de 1824 hasta la de $1917^{4}$ se negó a los pueblos indígenas su existencia como pueblos y culturas diferentes, partiendo, aparentemente, de la divisa de otorgar derechos iguales a todos los ciudadanos en territorio nacional como producto de las propuestas del liberalismo e individualismo que forjaron la construcción de los Estados nacionales. Ambas propuestas colocaron a los individuos como sujetos de derecho en la igualdad jurídica, donde la soberanía recae en el pueblo, entendiéndose como pueblo el conjunto de individuos iguales en derecho. En esta ficción de igualdad se permitió la existencia de la desigualdad como producto del desconocimiento de la diferencia. México forjó así su sentido de igualdad, creando una asimetría social mayor de la que pensaba erradicar.

Del modelo de configuración jurídica que cada Estado asuma sobre cómo definir las diferencias dependerán las formas posibles de relacionarse entre los sujetos individuales y los colectivos. Por ello Ferrajoli (2002) propone asumir en la actualidad la siguiente premisa: «... igual valoración jurídica de las diferencias», es decir, garantizar a todos su libre afirmación y desarrollo y no dejarlos a merced de la ley del más fuerte sino, más bien, hacerlos objeto de estas leyes mediante los derechos fundamentales. ${ }^{5}$ 
Lo que actualmente sucede, según Ferrajoli, es que bajo un modelo de indiferencia o de homologación jurídica las diferencias aparecen ignoradas de hecho y de derecho también. $\mathrm{Si}$ en cambio se asume la igualdad como una norma y la diferencia como un hecho, corresponde establecer en la normativa jurídica mecanismos de observación y de sanción para garantizar y respetar a los diferentes como iguales. Precisamente las diferencias - de sexo, de religión, de cultura, de etnia, entre otras - son las que deben ser tuteladas, respetadas y garantizadas; de ahí el reto contemporáneo jurídico y social de reflexionar y encontrar formas de convivencia más equitativas, específicamente con los pueblos indígenas de nuestro país.

Por ello, el conocer y reflexionar sobre los procesos de evangelización y de conversión no solo resulta útil para entender las discusiones jurídicas contemporáneas en México y en el ámbito internacional sobre derechos humanos religiosos y libertad religiosa, también contribuye a la comprensión sobre los puntos en controversia que orillan al conflicto y a la tensión en comunidades y pueblos indígenas en la actualidad.

\section{EVANGELIZACIÓN Y PROCESO DE CONVERSIÓN DE LOS NATURALES}

La evangelización y colonización de la Nueva España tuvo varios motivos: la expansión de la cristiandad; la obligación de evangelizar a los infieles, al mismo tiempo proteger y tutelar a los indios - infieles — para la defensa de la fe, y el desarrollo de un poderío económico y político de la Corona española. Por ello se dice que la evangelización se dio con «la Cruz y la Espada» ${ }^{6}$, ya que permitía justificar la violencia y el exterminio de los naturales por ser éstos infieles e idólatras y cuestionar su calidad o no de humanos, ${ }^{7}$ pues la conquista y la colonización establecieron un binomio entre el poder secular y el religioso indisociable. 
Tanto el poder secular como el religioso se legitimaron mutuamente para violentar los derechos de los pueblos conquistados, además intentaron sistemáticamente borrar las culturas y el patrimonio cultural de los pueblos originarios. Hasta la fecha se mantiene esta línea de excluir a dichos grupos de los derechos humanos colectivos y por ende también de los religiosos.

La conquista de América creó una forma entretejida entre hacer la guerra y cristianizar, en virtud de la cual las matanzas se justificaban por un fin apostólico: evangelizar. Al mismo tiempo, como nos dice Valero (2002), la incapacidad imperial de crear argumentos legitimadores para hacer la guerra, para ordenar el mundo de ese otro como totalmente distinto, casi humano y susceptible de ser dominado y esclavizado, y compaginarlo con la visión del otro como culturalmente semejante, por tanto susceptible a la cristianización, creó una constante contradicción que, a mi juicio, se mantiene aún en la actualidad.

Por ello, es importante atender el proceso de cristianización desde el siglo XV respecto a los pueblos conquistados, ya que se puede observar una relación desigual y clara de los evangelizadores frente a los posibles conversos. Esta relación de superioridad y de mandato divino para cristianizar, como elemento fundamental para que los naturales adquirieran completamente su humanidad, ha sido hilo conductor a lo largo de la historia no solo del continente americano, sino también de todas aquellas regiones que fueron sujetas a la conquista y colonización en África y Asia, y aún hoy sigue justificando procesos de evangelización y, en general, de proselitismo de toda religión considerada universal.

Es decir, la evangelización es un proceso constante y depende de ordenamientos legales así como de cada grupo religioso, y también de cómo estos vean o asuman a los posibles sujetos para la conversión, por lo que se requiere un acercamiento hacia los derechos humanos religiosos, a la libertad religiosa, y a los pueblos indígenas y tribales, como parte de una agenda contemporánea que permita, dentro del marco legal y social: una mirada desde la pluralidad de estos pueblos que fueron colonizados y cuya reinserción desde una situación político-jurídica edificante es hoy necesaria. 
En estos tiempos podemos apreciar los efectos de esa deslegitimación de la conquista: la discriminación, el racismo, la sumisión, la no valoración de la cultura propia; del mismo modo la evidente invisibilización de los pueblos indígenas como culturas diferentes y vivas, lo que sin duda representa un riesgo de colapso de la identidad cultural mesoamericana. En este sentido Mutua $(1996,2002)$ argumenta que el resultado del proceso de conversión forzada ha violentado necesariamente la conciencia individual y la expresión comunal de los pueblos africanos; al subvertir las religiones propias, se les ha robado a los africanos la esencia elemental de su humanidad; podemos decir lo mismo respecto a la situación de los pueblos indígenas del continente americano.

Para Mutua, se trata de un robo de la esencia elemental de su humanidad, y uno de los aspectos en los que se ve enfatizada esta pérdida de la identidad cultural y del reconocimiento de su humanidad es la pérdida de la memoria histórica, la disrupción de la memoria, ${ }^{8}$ disrupción respecto a las matrices fundadoras, así como el avasallamiento individual y cultural (Florescano 2000). Actualmente esta forma de pensar es la constante en muchas comunidades indígenas, mismas que en general no atribuyen valor alguno a sus propias expresiones religiosas y culturales por considerarlas inferiores y como signo de pobreza y discriminación. Viven en muchos casos en una tensión constante entre olvidar, renunciar o valorar y defender una forma de vida.

No obstante lo violento de la conquista y la evangelización, que trató de borrar y transformar la cultura y por ende las formas de organización política, social y religiosa ${ }^{9}$ sabemos que parte de esa memoria colectiva, de ese pasado, quedó en los ámbitos más próximos: en el individuo y en la familia — los valores individuales, familiares, y su relación con los dioses y protectores, se mantuvieron intactos- ${ }^{10}$. En algunos lugares encontramos elementos ciertamente interconectados ya con la memoria católica, creando así expresiones indígenas católicas, las cuales tienen referentes en las expresiones religiosas mesoamericanas. López Austin (2002) nos habla de la existencia de estas dos formas - la indígena y la católica - que implican una combinación difícil: han sido vehículos tanto de dominación y de penetración de ideas externas como de mecanismos de defensa ante la 
opresión. Se puede encontrar lo comentado en los relatos indígenas sobre la creación del mundo, sobre su origen como hombres y como pueblos, la inclusión de nombres y pasajes bíblicos como parte de la cosmovisión resimbolizada, lo cual expresa claramente esta combinación de universos que construyen realidades que dan coherencia a la nueva situación generada desde la Colonia.

Podemos encontrar también manifestaciones religiosas indígenas que, en una condición de subordinación y dominación, persisten y se practican de manera secreta y en silencio en los pueblos indígenas contemporáneos: en las cuevas, en los ríos, en los mismos pueblos, de noche y bajo estricta discreción.

Las nuevas configuraciones religiosas que resultaron de la conquista y de la colonización surgieron como diversas y complejas y de una riqueza simbólica tal que permiten aún hoy que muchos pueblos definan su identidad a través de ellas.

No obstante esa permanencia y vitalidad, las diversas manifestaciones cristianas ${ }^{11}$ persisten en considerar a los indígenas $-\mathrm{y}$ por ende sus expresiones religiosas - como sujetos de evangelización. Desde la perspectiva católica se mantiene una línea hacia la depuración de elementos paganos con el fin de lograr que los indígenas se humanicen en la plena expresión de una vida cristiana. Para la diversidad protestante y paracristiana significa también ganar almas, «recristianizar bien», ya que los católicos no lo lograron — situación que continúa hasta nuestros días.

Por ejemplo, todas las asociaciones religiosas siguen considerando a los indígenas como humanos inferiores que pueden llegar a ser completamente humanos en la medida en que dejen sus prácticas religiosas ancestrales, las cuales son percibidas como una etapa de evolución inferior. Pude constatar la existencia actual de esta forma de pensar en Tuxtla Gutiérrez, capital del estado de Chiapas, donde todas las Iglesias cristianas y paracristianas se unieron en un acto ecuménico, en 1992, para demandar su derecho a evangelizar a los indios. $^{12}$ 


\section{DERECHOS HUMANOS Y PUEBLOS INDÍGENAS}

Uno de los derechos fundamentales es el de la libertad en todas sus manifestaciones. Ya desde el siglo XVII se reconocía la libertad de conciencia y se hablaba de libertad religiosa, pero sin llegar a establecer derechos religiosos; también se hablaba de tolerancia y, muchas veces, de una tolerancia restringida. ${ }^{13}$ Fue hasta finales del siglo XVIII y XIX que en las constituciones nacionales se incluyeron planteamientos claros sobre libertad religiosa y de conciencia. Hasta mediados del siglo XX, internacionalmente se crearon los mecanismos institucionalizados para elaborar e implementar un documento medianamente consensuado, que pretendía ser universal en términos de los conceptos generados sobre derechos humanos universales y sobre los derechos humanos religiosos, éstos consecuencia de los primeros. Apenas a finales del siglo XX, en 1993, se inició una crítica a la universalidad de los conceptos y la asimetría en la toma de decisiones y acciones. La crítica ha sido planteada por los países no occidentales, principalmente por aquellos donde no hay separación entre los ámbitos religioso, social y político. Los comentados ordenamientos jurídicos internacionales soslayan las relaciones de poder y las diferencias culturales existentes, creando con ello más conflictos. A pesar de las intenciones de generar ordenamientos jurídicos y sociales que permitan una mejor convivencia, el concepto de universalidad no resuelve los problemas ni las tensiones.

Ahora quisiera dirigir la mirada hacia los actuales conflictos socioreligiosos en nuestro país. Se dan en una sociedad que se asume «democrática liberal» donde conviven grupos y comunidades que privilegian el bien común; aparentemente existe una contraposición de intereses entre los individuos y el colectivo. El Estado debe proteger y no traspasar los intereses de los individuos, sujetos fundamentales en su relación con la sociedad; debe velar por establecer un equilibrio entre las dos partes. De esta manera, México se asume pluricultural, y las reformas constitucionales iniciadas en 1992 al artículo 130 en materia religiosa y al artículo 2 en 2001 en materia indígena fortalecen la idea de un Estado plural. 
Esta segunda reforma constitucional en materia indígena ${ }^{14}$ representa un retroceso en el reconocimiento de la diversidad cultural de los pueblos originarios, y ha significado también un retroceso en materia de los derechos humanos de la segunda, tercera y cuarta generación, ya que al no incluir la diversidad cultural deja de lado la dimensión sociocultural donde los individuos se desarrollan y crean sus vidas.

En la realidad mexicana, el Estado, por más plural que diga ser y se muestre frente a la mirada internacional, no resuelve la situación real de reconocimiento político y social de los pueblos indígenas, quienes se estructuran según otras estrategias — las cuales privilegian el bien común-, y que gracias a una fuerte cohesión interna y al rechazo del individualismo han podido resistir y sobrevivir hasta la fecha. Es diferente la situación de aquellos individuos que si bien forman parte de grupos o comunidades religiosas y en consecuencia tienen vida social y comunitaria, aprovechan los preceptos que emanan del liberalismo, de manera que su bien común, en tanto no cae en fundamentalismos, vive dentro del ideal liberal. Dichos grupos se sustentan en el concepto y práctica de la tolerancia, en general, y en particular de la religiosa, para garantizar la diversidad y la diferencia con el fin de no caer en el abuso de la mayoría, así como para poner límites importantes a posturas de pensamiento y acciones absolutistas e incondicionales; como las que obedecieron, en el inicio de la modernidad, al principio «cuis regio, eius religio» ${ }^{15}$.

Hoy el reto está en limitar y regular las diferencias no solo en un marco de igualdad formal, sino de igual manera tomando en cuenta las diferencias reales, o sea, es necesario cambiar a un marco conceptual y legal que incluya la equidad efectiva.

La importancia de la comunidad responde a que no es posible ubicar al individuo en abstracto, aunque de facto se ha instaurado esta idea a través de la Declaración Universal de los Derechos Humanos; la creación de los Estados nacionales sustentados en una política y filosofía del liberalismo hasta nuestros días pretende a toda costa crear una unidad nacional allí donde no la hay y una idea universal de individuo en abstracto. El reto está -y siempre ha estado - en asumir la diversidad y la equidad. Esto implica dejar de lado las propuestas 
en abstracto y establecer acuerdos entre los diferentes integrantes sociales de cada Estado a partir de realidades concretas. México requiere incluir a los pueblos indígenas de una manera efectiva y en la paridad.

Sin embargo, cuando los Estados están construidos sobre la base de la existencia de culturas distintas - ya sea que las reconozca o no-, como es el caso de México, es necesario reconocer y respetar los sistemas de creencias, los valores, las soluciones posibles y la capacidad de elección libre a la que pertenece cada comunidad cultural. En este sentido Villoro (1999) nos dice que los Estados multiculturales no pueden o no deben dar por hecho que todos pertenecen a la misma unidad cultural, ${ }^{16}$ por lo tanto, tampoco es posible asumir valores colectivos homogéneos, más bien, se debe asumir el reconocimiento de las diferencias. Bajo esta perspectiva, los derechos humanos han de incluir una referencia al derecho de las comunidades culturales a las que pertenecen los individuos, en las cuales el ejercicio de la libertad personal de cada quien debe darse en el seno de la cultura a la que pertenece. En este contexto Villoro habla del derecho a la autonomía personal, la cual incluye la conciencia de la propia identidad como miembro de una colectividad.

El «derecho de los pueblos» solo puede contarse entre los derechos humanos fundamentales en la medida en que «pueblos» sea una condición necesaria para la autonomía de las personas; entonces solo puede referirse a la comunidad cultural en cuyo marco se da cualquier elección autónoma; en esa medida, el «derecho de los pueblos» no contradice los derechos del individuo, sino por el contrario los refuerza (Villoro 1999: 94).

Finalmente el marco legal internacional y nacional ${ }^{17}$ está inscrito, todavía hoy, en una dinámica que centra las argumentaciones legales y morales en el concepto de individuo, precepto que se ha convertido casi en una nueva religión ya que existe la pretensión de asumirlo como universal y, por ende, como un ente abstracto y sagrado. Por tal motivo es esencial discutir y analizar estos fundamentos en los instrumentos legales internacionales y nacionales con el fin de conocer cuáles son las relaciones entre los Estados, las sociedades, los pueblos indígenas, y los grupos religiosos, para así poder ubicar la relación entre los 
sistemas religiosos y la construcción o no del concepto «libertad religiosa», así como la inclusión o no de estas problemáticas en las constituciones nacionales y la operación de estas disposiciones en concreto.

\section{Derechos humanos RELIGIOSOS CONTEMPORÁNEOS ${ }^{18}$}

Para entender este tema es necesario comenzar con un panorama internacional que posteriormente aborde el marco nacional, lo que permitirá comprender asuntos locales y la inserción de diferentes actores en el escenario de los derechos humanos religiosos. Hasta la fecha el sistema legal internacional no ha generado un tratado vinculante ${ }^{19}$ general con respecto a los derechos religiosos.

La Declaración Internacional de las Naciones Unidas sobre la Eliminación de todas las formas de Intolerancia y Discriminación basada en la Religión o Convicciones (EIDRC), emitida en 1981, es el instrumento más importante referido a los derechos religiosos. Sin embargo, vale la pena señalar que el proyecto del pacto está todavía pendiente en la Naciones Unidas, pues su implementación se ha visto dificultada por las discusiones y desacuerdos de diferentes países sobre los contenidos. Por este motivo no es, como mencioné, un instrumento mandatorio. ${ }^{20}$

La existencia de un marco jurídico internacional sobre pactos y declaraciones que considera artículos que regulan lo religioso permite constatar la importancia de abordar el tema de los derechos, ya que encontramos el ámbito de lo religioso prácticamente en todas las actividades de los individuos y grupos; de ahí la necesidad de la instrumentación de provisiones legales que garanticen los derechos religiosos no solo colectivos sino también individuales. 
La dificultad estriba en la gran diversidad de expresiones religiosas, pues sus prácticas inciden en los ámbitos social, cultural, educativo, económico, político, que a la vez derivan o se vinculan con otras instancias de la vida social y, por tanto, afectan las relaciones interpersonales, grupales, estatales, nacionales e internacionales, de lo que resulta la imposibilidad de establecer un instrumento legal internacional obligatorio. ${ }^{21}$ Esto conlleva el riesgo de aceptar un mínimo de protecciones para evitar conflictos entre los países, lo que implicaría no tener un consenso amplio, dada la colisión de sistemas legales nacionales e internacionales - cuya estructura y visión de vida se contraponen a los derechos humanos religiosos. Este sería el caso de la mayoría de los países musulmanes o de aquéllos en los que hay prohibición explícita sobre cultos religiosos.

No está dentro del alcance del presente trabajo hacer un análisis exhaustivo de las distintas provisiones con respecto a los derechos religiosos contenidas en los diferentes pactos, pero sí hacer algunos señalamientos al respecto que permitan acercarnos a los conflictos religiosos en México y sus relaciones con los pueblos indígenas.

Uno de los logros importantes de la Declaración sobre la Eliminación de todas las formas de Intolerancia y Discriminación basada en la Religión o Convicciones (DEIDRC) — dice Lerner (1996) - es que propone un acercamiento individual y colectivo a los derechos religiosos. Esto es importante para el reconocimiento no solo de organizaciones religiosas sino también, fundamentalmente, de colectividades o comunidades de origen religioso, donde lo religioso aparece en combinación con características étnicas y culturales (Lerner [1996] p. 132).

Gracias a la DEIDRC se han establecido arreglos y convenios entre Estados y grupos religiosos o comunidades con orientación religiosa, a partir de reconocimientos específicos (ibid); tal es el caso de México, que en 1991 reformó el artículo 130 constitucional sobre cultos religiosos para otorgar personalidad jurídica a las asociaciones religiosas, ${ }^{22}$ lo cual ha propiciado relaciones abiertas y directas entre el gobierno y las asociaciones religiosas. Sin embargo, en estas reformas no se ve plasmada la existencia de sistemas de creencias 
indígenas, ni mucho menos una reglamentación que permita un vínculo y coherencia con la reforma constitucional, en materia indígena, al artículo 2 constitucional de 2001.

Otro aspecto más tiene que ver con las controversias sobre los procesos de conversión, con los derechos de las mujeres y de la niñez y con la objeción de conciencia por creencias religiosas, de donde surge un cuestionamiento sobre los límites de los derechos religiosos; es decir, hasta qué punto debe haber prohibiciones o límites a la libertad religiosa, por incitamiento en contra de grupos religiosos y la libertad de asociación y libre expresión (ibid, p. 133). ${ }^{23}$

Tema igualmente fundamental es el que se refiere al relativismo cultural y al universalismo, donde parece legítimo, dice Lerner — y nos adscribimos también a esto-, respetar algunas formas particulares del comportamiento grupal y, por lo tanto, de grupos religiosos, proveyendo un estándar mínimo en el ámbito internacional para prevenir la laceración de los derechos humanos (ibid). Esto es indispensable para garantizar los derechos culturales de grupos que históricamente se encuentran en situaciones vulnerables — como serían los Derechos de los pueblos indígenas, ${ }^{24}$ entre otros grupos-, y que recientemente han sido incluidos en las disposiciones legales internacionales de las Naciones Unidas. ${ }^{25}$ No obstante que en la actualidad existe ya una Declaración Universal sobre Derechos de los Pueblos Indígenas, esta sigue siendo insuficiente, y cabe decir que, para el caso mexicano, el presidente en turno, Felipe Calderón, sí reservó seis artículos referidos principalmente a la autonomía, libre determinación, autogobierno, territorio, etc.; estos artículos, por lo pronto, son clave para la supervivencia de los pueblos indígenas. Si tomamos en cuenta no solo las reservas que en México se han hecho, junto con el no considerar los sistemas de creencias como parte elemental de sus derechos, podemos decir que la Declaración Universal no ayudará significativamente a abonar la discusión y garantía de derechos culturales plenos y, por ende, de sus derechos religiosos. Sin embargo, no tengo duda de que esta declaración sí contribuirá a una reflexión académica, de los pueblos mismos y de defensores de los derechos de los pueblos indígenas, para profundizar en las garantías y reflexionar sobre los 
derechos no contemplados, en este caso, sobre los derechos religiosos de los pueblos indígenas.

Por ello, podemos decir que independientemente de algunos problemas, no solo para su instrumentación vinculante y en relación con otros derechos e intereses políticos e incluso religiosos, los derechos humanos religiosos han ejercido una influencia favorable sobre las naciones. $^{26}$

\section{LIBERTAD RELIGIOSA Y ESTADOS NACIONALES}

Las tendencias actuales respecto a los derechos humanos se encaminan hacia el aumento y la exacerbación de la diversidad cultural $^{27}$ — demandas de la tercera generación de derechos- ${ }^{28}$ junto con la construcción de un orden global, en el cual los derechos humanos se han vuelto una pieza que permea gran parte del pensamiento del mundo pero que, como hemos visto, está centrada en el ideal liberal del individuo (Van der Vyver 1996: IXXLVII). Con ello no se está dando una solución eficiente a los reclamos que garantice derechos de la diversidad cultural.

Se genera una tensión entre la necesidad de establecer un concepto de derechos humanos y libertad religiosa que permita crear consensos y garantías, y la necesidad de incluir la diversidad. Sin embargo, lo que hay en realidad es una variedad de percepciones y estructuras de valores (Van der Vyver 1996: XV) que se relacionan íntimamente con las estructuras políticas. Lo que interesa aquí es la relación entre los Estados y los sistemas religiosos, ${ }^{29}$ que queda plasmada en las constituciones nacionales, ${ }^{30}$ y la permeabilidad o no del sistema jurídico en las relaciones cotidianas entre individuos, colectivos, y el Estado, frente a grupos religiosos o viceversa.

El comprender la relación entre los sistemas religiosos y la autoridad del Estado permite conocer las formas varias que existen para evitar las tensiones, los conflictos e incluso las matanzas por motivos religiosos; aunque también puede mostrar cómo a partir de los 
Estados se genera violencia hacia sectores de la población que manifiestan en parte sus diferencias a partir de lo religioso, como es el caso de los pueblos indígenas, en los cuales la diferencia no es solo religiosa, sino que también habla de configuraciones culturales distintas y complejas en un mundo cada vez más globalizado.

\section{CARACTERÍSTICAS DE LOS ESTADOS EN LA RELACIÓN ESTADO/IGLESIAS}

Los gobiernos y la sociedad han dado respuestas muy variadas al vínculo Estado/Iglesias, independientemente de haber firmado o no pactos internacionales relacionados con derechos religiosos y libertad religiosa. ${ }^{31}$

Las variantes son múltiples; sin embargo, podemos señalar algunos elementos. En general los Estados modernos asumen, con sus diferencias, una separación Estado/Iglesias, pero en todos hay una coincidencia: es el Estado, a través de sus leyes y constituciones, quien concede y limita la libertad religiosa; si bien hay países mucho más abiertos en este aspecto, donde la libertad religiosa es más clara, como Estados Unidos de Norteamérica.

En los países donde se dan relaciones entre Estado e Iglesias no existe tanta separación con el grado de libertad religiosa, pero sí puede haber situaciones donde algunas sean religiones de «segunda o tercera clase», como serían las religiones indígenas, que en ningún momento son contempladas claramente. La «marginalización de las religiones» ${ }^{32}$ lleva a los Estados a no contemplar regulaciones específicas. En este sentido también están las religiones de los países islámicos, donde hay cabida para algunas de éstas pero sus adeptos son considerados como de segunda clase.

En general hay conflictos persistentes entre sistemas religiosos y sistemas políticos, que aumentan en la medida en que la diversidad religiosa reclama derechos religiosos específicos que le ofrezcan cierta certeza jurídica y social.

Si a esto le agregamos la diversidad cultural y étnica, muchas veces vinculadas con las otras dos, la complejidad aumenta. En este sentido, el no reconocimiento de los pueblos indígenas y tribales de todo el mundo en la Declaración sobre la Eliminación de todas las 
formas de Intolerancia y Discriminación basada en la Religión o Creencias (EIDRC) y en las Declaraciones sobre derechos humanos, tiene la reiterada postura de crear un mundo homogéneo, sin considerar las necesidades y los requerimientos de ciertos grupos sociales y culturales. De ahí que las demandas de los pueblos indígenas y tribales de todo el mundo respecto a la conversión y al proselitismo no hayan tenido una respuesta positiva; por lo tanto, tampoco hay límites que garanticen la reproducción sociocultural de estos grupos. ${ }^{33}$

El caso de México es un buen ejemplo, no solo por el proceso democrático del país, merced al cual las reformas constitucionales al artículo 130 sobre cultos han cambiado su estatus internacional: de ser un país anticlerical a uno en donde se dan garantías religiosas y personalidad jurídica. Sin embargo, la insistencia cada vez mayor en la necesidad de proteger y garantizar los derechos de las minorías, llámense religiosas, de homosexuales, de mujeres, de niños, de enfermos, ${ }^{34}$ y en garantizar derechos a los pueblos indígenas, no como minorías sino como pueblos originarios; no ha dado aún frutos palpables a pesar de algunos cambios constitucionales y de haberse firmado pactos y declaraciones internacionales. Caso concreto lo tenemos con la actual reforma constitucional al artículo 2 en 2001 — Ley Indígena—, que contraviene algunas secciones del Convenio 169 de la OIT.

Los conflictos religiosos en zonas indígenas mexicanas están inscritos en una discusión sobre derechos humanos y derechos religiosos, y en una relación histórica de asimetría social que propone ubicar estos conflictos no en el esquema de los derechos humanos de la primera generación sino dentro de los de la segunda y tercera generación.

\section{CONFLICTOS RELIGIOSOS CONTEMPORÁNEOS: SIGLO XX Y XXI}

Los conflictos religiosos contemporáneos se dan en un contexto donde la relación Estado e Iglesias, y la relación entre feligresías e Iglesias, para el mundo cristiano, es a través de la separación de poderes, de la aceptación de la libertad de conciencia individual, y de la existencia del concepto de libertad religiosa; ${ }^{35}$ lo último incluye, entre otros elementos, a los dos primeros: la separación de poderes y la libertad de conciencia. Esto es, se limitan las 
esferas de acción y competencia de los tres actores en juego: 1) El Estado, como entidad reguladora del orden social, plurivinculado y de supremacía sobre las instituciones religiosas y sobre los ciudadanos. ${ }^{36}$ 2) Los sistemas religiosos, en tanto instituciones que permanecen y se desarrollan en sociedades determinadas, no tienen el control social ni religioso; son grupos univinculados. ${ }^{37} 3$ ) Los individuos, que tienen el derecho a decidir no solo sobre sus preferencias religiosas y sobre si tenerlas o no, sino también a conciliar sus relaciones con el ámbito secular y religioso. México, desde luego, queda inscrito en esta dinámica.

En tal contexto, lo que cambia es la ubicación social y legal de los conflictos religiosos, no así los tipos de conflictos. Siguen existiendo conflictos entre religiones, entre los sistemas religiosos en su interior y entre las opciones individuales y colectivas relativas a qué religión profesar, a no tener ninguna religión e incluso a poder estar en contra de cualquier religión, ya sea en el ámbito individual o como Estados nacionales. ${ }^{38}$

Ciertamente el proceso de secularización ${ }^{39}$ contribuyó a este cambio en la ubicación del ámbito religioso, del lugar y del tratamiento de los conflictos religiosos. Por un lado se consideró al sujeto como un individuo libre, con derechos humanos inalienables, con base en la libertad de conciencia individual y en un voluntarismo religioso (Wood Jr. op.cit, p. 475). Por otro, la secularización implicó que los sistemas religiosos pasaran a competir con, o a formar parte de, otros sistemas ideológicos por los que podían optar tanto individuos como Estados. Este proceso impulsó así un rechazo cada vez más evidente a la persecución e intolerancia religiosa que los sistemas religiosos insistían e insisten en mantener todavía. $^{40}$

También han coadyuvado a esta continuidad de los conflictos religiosos la depreciación o desvalorización de lo religioso y la priorización de valores seculares (Witte Jr. 1996: XXXIII). Al haber asumido, entre otras cosas, que la secularización llevaría a la desaparición de lo religioso, en efecto se dio una separación de poderes y un 
estrechamiento del ámbito sagrado, aunque esto no revirtió en la pérdida del sentimiento religioso.

Si bien el priorizar los valores seculares ha sido un paso importante, en la actualidad todavía sigue existiendo una tensión social constante ${ }^{41}$ entre la permanencia de los sistemas religiosos y la hegemonía del Estado. Esto se debe a que los sistemas religiosos son instituciones que tienen intereses políticos, económicos y de poder social, no solo frente a otras expresiones religiosas sino además frente al Estado o sociedad en los que se encuentren. $^{42}$

\section{DEPRECIACIÓN DE LO RELIGIOSO}

La depreciación desestima lo religioso, también se ha negado u ocultado que los sistemas religiosos son generadores de violencia, abuso y atropello. Esta situación ha provocado que tanto en las esferas internacionales como en las nacionales no se hayan asumido social y legalmente en una forma seria estos derechos, a pesar de que hoy se consideran los derechos religiosos como inalienables y fundamentales para la existencia y viabilidad de todos los demás derechos humanos. ${ }^{43}$

Al respecto nos dice Witte Jr. que hay tres consecuencias importantes de esta minimización de lo religioso, mismas que considero pertinente mencionar:

1) Desde una perspectiva individual, nos dice el autor, se coarta el derecho a creer, el cual conlleva ineludiblemente el derecho de reunión, de hablar, de adorar, de hacer proselitismo, educar o abstenerse de cualquiera de los anteriores por efectos de la propia creencia. Desde la perspectiva de las asociaciones religiosas, implica derechos corporativos a la propiedad, a la adoración colectiva, organizaciones de beneficencia, libertad de prensa, autogobierno, etc. Por otro lado, anota que la depreciación de lo religioso ha provocado la separación de los derechos de las obligaciones (op. cit., p. XXXIII). La supremacía del Estado en la toma de decisiones ha ocasionado que los grupos religiosos vivan de forma disociada los derechos y obligaciones hacia sus grupos religiosos y hacia la sociedad en general, pues 
están sujetos a las reglamentaciones estatales. Por lo mismo, el Estado no ve la realidad en la que viven los miembros de estos grupos, los cuales deben a veces cumplir con derechos y obligaciones que se contraponen; esto es, hay una contradicción entre aquellos derivados de sus filiaciones religiosas y los que les corresponden como miembros de una sociedad mayor.

2) La depreciación de los derechos religiosos ha agudizado los conflictos entre naciones, ya que otras naciones no pueden concebir y, por tanto, aceptar un sistema de derechos que excluya lo religioso. Es decir, el sistema religioso está íntimamente relacionado con cada aspecto de la vida; tal es el caso del islamismo, hinduismo, budismo, taoísmo, y de las religiones indígenas en todo el mundo. ${ }^{44}$

3) La depreciación, señala Witte Jr., ha sobrevalorado el papel del Estado como garante de los derechos humanos; prueba de ello es que se ha creado una serie de instituciones voluntarias privadas, e incluso las mismas instituciones religiosas, para mediar entre el Estado y los individuos con el objetivo de garantizar, en general, cualquier derecho humano, incluso el religioso (op. cit., pp. XXIII-XXXV). Debido al lugar hegemónico que ocupa el Estado moderno en la relación que establece con las instituciones eclesiásticas, a través de su laicidad México ha promovido también la depreciación de lo religioso.

Los conflictos religiosos en zonas indígenas de nuestro país nos llevan a reflexionar y a observar cuáles son las relaciones sociopolíticas que sustentan las relaciones entre los pueblos indígenas y el Estado, y los procesos de conocimiento que refuerzan la toma de decisiones y las construcciones de entendimiento de la realidad. Hemos visto cómo desde la época Colonial hasta nuestros días continúa una tendencia no solo hacia la invisibilización de los pueblos indígenas sino también a un no reconocimiento de los mismos como culturas diferentes y pueblos originarios de estas tierras, en virtud de la cual se les considera sujetos a «cristianizar», a «civilizar», a «integrar» al mundo contemporáneo desde una estrategia que consiste en borrar la diferencia cultural, y en nuestro caso en borrar la diferencia religiosa y desvalorizarla a tal grado que no esté contemplada como parte del acervo de su ethos cultural. 
Por ello, la depreciación o la minimización de lo religioso desde las ciencias sociales se vuelve un tema fundamental a tomar en cuenta; el no hacerlo ha dado lugar a sesgos importantes en la interpretación sobre los conflictos religiosos, al no asumirlos o restarles consideración. Ocurre así en los conflictos en zonas indígenas donde se les niega la íntima relación entre sistema religioso y organización social, además de priorizar otros sistemas religiosos en el concierto de derechos y obligaciones.

\section{LOS CONFLICTOS RELIGIOSOS EN COMUNIDADES INDÍGENAS Y DERECHOS RELIGIOSOS}

Los conflictos que se derivan de las conversiones religiosas en las áreas indígenas en México han demostrado tener mayores índices de violencia y repercusión social ${ }^{45}$ debido a la contraposición de intereses individuales y colectivos y por la defensa de creencias que no pueden ser reducidas ni condicionadas.

Estos conflictos, normalmente unidos con otras problemáticas sociales, ponen en la mira del Estado a los actores sociales en cuestión y a los mecanismos y agentes especializados que deben dar solución a los casos. ${ }^{46}$

Las denuncias sobre conflictos religiosos y demandas en contra de los pueblos indígenas como violadores de derechos humanos, y la exigencia de castigar a sus autoridades como responsables directos de dichos actos, han ido en aumento a partir de 1992 debido a las modificaciones del artículo 130 constitucional en materia religiosa, en virtud de las cuales las asociaciones religiosas obtuvieron personalidad jurídica y un lugar social evidente.

Por un lado se tienen aspectos jurídicos y políticos, y por otro aspectos socioreligiosos que marcan diferencias en términos de cosmovisión, donde los sistemas religiosos forman parte nodal de la organización social pero en los cuales, como ya vimos, los pueblos indígenas no están cabalmente representados. 
En cuanto a la libertad religiosa, el problema radica en que se la sitúa dentro de una sociedad determinada, en este caso la mexicana, que establece constitucionalmente la libertad de culto y de conciencia, privilegiando al individuo como sujeto de derecho. En este sentido, la Constitución y los convenios internacionales defienden y avalan tanto los derechos humanos universales, fincados en el individuo, como los derechos religiosos y los derechos de las minorías, y otorga cierto reconocimiento a los derechos de los pueblos indígenas. $^{47}$ Esto plantea una aparente contraposición entre derechos individuales y culturales e intereses políticos internos y externos, como lo señalé en el inciso anterior.

El problema se centra en el choque de sistemas jurídicos y de sistemas de visión del mundo en un marco de referencia social, pluricultural y plurirreligioso, en una sociedad que aún no desarrolla muchos de los referentes constitucionales y legales de manera que se reflejen en la impartición y procuración de justicia. Las posiciones ideológicas no permiten entender ni solucionar los conflictos religiosos en las zonas indígenas. La opinión pública ha creado un consenso que contribuye a la desigualdad de circunstancias en esta sociedad, en virtud del cual los pueblos indígenas no se ven incluidos cabalmente en la Constitución ni se reconocen públicamente sus derechos culturales $\mathrm{y}$, por ende, tampoco los derechos religiosos que son parte inherente de sus culturas.

Hablar de las expresiones religiosas indígenas requiere, desde luego, profundizar sobre esta complejidad cultural en la que hay una diversidad de expresiones religiosas y donde los vínculos con lo católico o con grupos evangélicos tienen gradientes diversos; por ello es necesario, por ahora, no desvincular el sistema de creencias religiosas de los derechos de los pueblos indígenas como un todo, ya que el llevar a cabo una separación como instituciones independientes, semejante a la estrategia occidental, es lo que no ha permitido comprender varios aspectos de este tipo de conflictos. ${ }^{48}$ 


\section{LAS COMUNIDADES INDÍGENAS. LAS ASOCIACIONES RELIGIOSAS.}

\section{LOS SISTEMAS JURÍDICOS}

En la actual coyuntura, donde se debaten problemas sobre autonomía indígena, democracia y defensa de los derechos humanos, es de suma importancia atender y dar cuenta de los conflictos religiosos, no solo por el hecho que se den en sí mismos sino además por las implicaciones individuales y colectivas que se derivan de ellos en términos de pertenencia y viabilidad social; esto implica un reconocimiento político de las demandas culturales dentro de una sociedad plural que permita el desarrollo y fortalecimiento de sus integrantes.

Los conflictos religiosos en las comunidades indígenas nos obligan a observar el hecho en función de la correlación de fuerzas sociales y políticas:

1. El campo religioso se considerará heterogéneo y mediado por las normas jurídicas nacionales.

2. Existen relaciones sociales que marcan correlaciones de fuerzas diferenciadas que provocan socialmente una ideología de intolerancia. Por un lado, se privilegia al individuo y a aquellos grupos que entran dentro de la lógica de los derechos humanos religiosos y de la libertad religiosa, cuyos preceptos concuerdan con el ideal democrático que se enarbola $\mathrm{y}$, por otro, se rechazan, se reprimen o minimizan los derechos de aquellos individuos o colectivos que no encajan fácilmente con el ideal de democracia y de tolerancia aceptado y avalado por el Estado. Entendida la tolerancia ${ }^{49}$ como un instrumento del Estado que crea consenso y coerción, y no realmente mediaciones que garanticen relaciones más equilibradas entre las partes, se convierte «en una discriminación encubierta y ... meramente retórica» (Valadés 2002a: 103), o como dice Marcuse (1968) una «tolerancia represiva», en tanto no crea igualdad de circunstancias sociales ni jurídicas.

3. La característica del fenómeno religioso como altamente intolerante de otros fenómenos sociales obedece a que busca y promueve verdades absolutas. 
Las resoluciones endógenas de las autoridades y comunidades mismas pueden parecer, desde afuera, arbitrarias y ajenas a la lógica occidental, como en el caso de las expulsiones, restricciones o pérdida de derechos comunales. Sin embargo, a los externos se nos olvida, por una idea de supremacía y en ocasiones por un desconocimiento profundo, lo que son los sistemas religiosos en las comunidades indígenas, así como lo importante que resultan para el mantenimiento y desarrollo de las comunidades sus sistemas de creencias, los cuales han perdurado a lo largo del tiempo y representan en gran medida su identidad.

El elemento religioso es punto central en la construcción de identificación, de diferenciación y de permanencia, misma que en la actualidad representa una de las más claras reivindicaciones socioculturales a escala mundial.

La existencia de todo un sistema de organización social y jurídica paralelo al sistema de ordenamiento nacional dificulta las relaciones y la delimitación de funciones entre lo nacional y las comunidades indígenas. Esta relación de choque entre sistemas se hace patente al interactuar social y jurídicamente. Por ello, los conflictos religiosos se vuelven un elemento de difícil solución jurídica y no se dirimen por este camino, principalmente porque demuestra su ineficacia y porque al Estado le es más cómodo no tener antecedentes jurídicos en esta materia. Como resultado de ello, suele darles solución mediante la coerción, la represión, el desgaste, y la imposición del ámbito constitucional, en detrimento no solo de las formas jurídicas internas sino también de las formas culturales que marcan - o hasta ahora han marcado- la pervivencia de las culturas indígenas. Por este motivo se ha creado una Subsecretaría de Asuntos Religiosos, dependiente de la Secretaría de Gobernación, que intenta solucionar los conflictos e imponer soluciones generalizadas; se dice con «estricto apego a la ley», merced al cual los pueblos indígenas se ven forzados, a través de la institución, a aceptar a los conversos en sus comunidades como signo de su inserción jurídico-política. Dichos convenios generalmente provocan mayor conflicto o quedan sin firmar. 
Si se habla de los conflictos por conversiones, la situación se complica en varios niveles por:

a) el lugar y posición de los indígenas dentro de la estructura social nacional — sus derechos y obligaciones como ciudadanos mexicanos-;

b) el lugar de los evangélicos en el ámbito nacional — sus derechos y obligaciones—;

c) la legitimidad y legalidad del sistema nacional hacia afuera de la comunidad y hacia dentro de la comunidad indígena;

d) la ubicación dentro del sistema jurídico tanto de los pueblos indígenas como de las asociaciones religiosas,

y e) la violación de los derechos individuales y colectivos a los que ambos están sujetos.

En cuanto al último punto, derechos individuales y colectivos, parece que es necesario trabajar sobre los conceptos y la representatividad de los mismos, y también sobre el orden político y jurídico estatal en el cual se cristalizan las decisiones políticas relacionadas con el establecimiento o no de una situación equilibrada entre lo comunitario y lo individual, más que sugerir que la solución está en los principios generales sobre derechos humanos de la primera generación. ${ }^{50}$

Por lo que en los casos de conflicto religioso no es posible considerar como intransigentes solo a los indígenas, cuando la intolerancia es inherente a los sistemas religiosos universalistas y proselitistas como es el cristianismo. El no respeto viene también de aquellos que quieren misionar y convertir, violentando su privacidad, sus costumbres y formas de organización.

Finalmente, la puesta en escena de un Estado plural en México, reitero, se ha vuelto más bien una cuestión de retórica jurídica y política, donde los instrumentos legales y sus estrategias aún hoy no están claros ni mucho menos dan viabilidad a la existencia real de un pluralismo jurídico. 


\section{CONCLUSIÓN}

Por todo lo expuesto, es necesario mantener una constante reflexión sobre qué es lo que está en juego en cada conflicto o tensión religiosa y cómo se despliegan los escenarios, los intereses colectivos e individuales desde lo local. Creo que uno de nuestros retos, desde la antropología jurídica y desde la sociedad en general, es mantener clara la relación y la tensión entre lo local, lo nacional e internacional, sin perdernos en los esquemas macrosociales como son las relaciones y ordenamientos internacionales, aunque sin ignorarlos tampoco, porque hoy más que nunca los ámbitos micro y macro se tocan y se desdibujan constantemente; se nutren e influyen directamente en las vidas de individuos y colectivos en el ámbito local y, por ende, en el ámbito macrosocial, que se asume íntimamente involucrado con aquello que le sucede a un individuo o grupo a partir de las nuevas configuraciones globalocalizadas.

Así es indispensable seguir examinando las relaciones y correlaciones de fuerza entre el Estado mexicano, las asociaciones religiosas, los pueblos indígenas, y la sociedad en su conjunto; puesto que nos hablan de cómo se construyen las identidades, las formas de pensar, de actuar: las maneras en que se hacen y se reproducen las culturas en un mundo cada vez más complejo donde la subjetivización individual y colectiva cobra mayor sentido y, consecuentemente, hay también una mayor recurrencia a establecer vínculos y estrategias que hablen sobre la justicia pero, más aún, que hagan justicia.

Se suma el vínculo evidente entre lo jurídico, lo social, y lo religioso, que crea una problemática social en cuyo estudio la antropología jurídica encuentra un punto nodal ejemplo es la ya vieja relación entre el derecho y lo religioso, que hoy también se vincula con la defensa de los derechos humanos, la justicia, los reclamos sociales y culturales-, donde las interconexiones y colisiones entre sistemas de vida y derechos creados o reivindicados a través del proceso de construcción de la subjetivización individual y colectiva agudizan y visibilizan aun más los puntos complejos como, en el caso que nos ocupa, los conflictos religiosos. Estos conflictos se han vuelto no solo un punto difícil de 
litigio sino también una controversia irresoluta debido al modo en que hemos sido acostumbrados a mirar el mundo a través de verdades absolutas, y los puntos de encuentro están desde luego mediados por la injusticia y la correlación de fuerzas.

Finalmente, podemos decir que aún hoy los derechos de los pueblos indígenas siguen estando consignados constitucionalmente de forma deficiente, puesto que no se establecen regulaciones ni reglamentaciones, y la evidente ausencia de un pluralismo jurídico nos permite ver la vulnerabilidad de facto de sus derechos — por ejemplo, sus derechos religiosos-. Esto nos indica el largo camino que todavía tenemos que recorrer para garantizar derechos en la equidad y en la igualdad. 


\section{BIBLIOGRAFÍA}

Barabas, Alicia M., 1995, «Iglesias y religiones: dominación colonialista y resistencia indígenas». En Articulación de la Diversidad. Tercera Reunión de Barbados, coordinado por G. Grunberg, núm. 27, pp. 99-121. Biblioteca Abya-Yala, Quito.

—, 1997, «Movimientos socio-religiosos indios en América Latina». En Religión y etnicidad en América Latina, compilado por German Ferro, tomo II. Memorias del VI Congreso Latinoamericano de Religión y Etnicidad, ALER, y II Encuentro de la diversidad del hecho religioso en Colombia, ICER. Instituto Colombiano de Antropología.

—, 2000, «La construcción del indio como bárbaro, de la etnografía al indigenismo». En Alteridades, año 10, núm. 19, enero-junio, pp. 9-20. UAMI, México.

Bartolomé, Miguel, 1996, Pluralismo cultural y redefinición del Estado en México. Departamento de Antropología, Universidad de Brasilia, CESPE/UNB. (Serie Antropológica, núm. 210.)

—, 1998a, «Religiones nativas e identidades étnicas en México». En Religiones y Sociedad, núm. 2, enero-marzo, pp. 55-77. SG, Asuntos Religiosos, México.

—, 1998b, «Proceso civilizatorio, pluralismo cultural y autonomía étnicas». En Autonomía étnicas y nacionales, coordinado por Miguel Bartolomé y Alicia Barabas. Conaculta/INAH, México.

Bloom, Martin, et al., 1996, Religious diversity and human rights. Columbia University Press, Nueva York.

Borja, Rodrigo, 1991, "El estado y la iglesia" en Derecho político Constitucional, 2ed. C.F.E., México pp.236 - 243.

Caney, Simon y Peter Jones, (eds.) 2001, Human rights and global diversity, Frank Cass, London

Carbonell, Miguel, 2001, «Minorías etno-culturales y derechos colectivos: premisas conceptuales». En Derechos humanos, editado por Diego Valadés, pp. 55-70. Memoria del IV Congreso Nacional de Derecho Constitucional III. IIJ/UNAM, México. (Serie Doctrina jurídica, núm. 64.) 
Carmagnani, Marcello, 1993, El regreso de los dioses. El proceso de reconstrucción de la identidad étnica en Oaxaca. Siglo XVII y XVIII. lera. Reimpresión, FCE, México. (Sección obras históricas).

De Lucas, Javier, 2003, «¿Qué quiere decir tener derecho a la cultura?». En Derecho Social. Instrucciones de uso, compilado por Abramovich, M. Añon, Ch. Courtis, pp. 297-320. Fontamara, México. (Serie Doctrina jurídica contemporánea, núm. 14.)

Durkham, Cole 1996, "Perspective on religious liberty: A comparative framework", en van der Vyver, Johan y John Witte, Jr (eds) Religious human rights in global perspective. Legal perspective, vol. 2, Martinus, Nijhoff Pub., The Hague/ Boston/ London, 1-44pp

Esteva, Gustavo, 1995, «Derechos humanos como abuso de poder». En Kiwira, núm. 44, pp. 24-36. Diócesis de Tarahumara, Chihuahua, México.

Fabre Zarandona, Artemia, 1992a, Historia y desarrollo de la diversidad religiosa en México. INI, México. (Cuadernos de trabajo.)

—, 1992 b, «La diversidad religiosa en México». En El Día Latinoamericano, 9 de marzo, México, p. 14.

—, 1995, «Religión y conflicto social en Oaxaca: entre el abuso de la autonomía y el ejercicio de la libertad religiosa». En ¿Persecución religiosa en Oaxaca?, coordinado por Marroquín, pp. 123-173. IOC/IIS UABJO/FONCA, México. (Colección Dishá.)

—1999, «Conflictos religiosos: pueblos indígenas, conversos, asociaciones religiosas y colisión de sistemas jurídicos». En América Indígena, Vol. LVIII, núms. 1-2, enerojunio, pp. 321-340. IIJ/INI, México.

—, 2005, «Libertad religiosa y colisión de sistemas jurídicos. Los pueblos indígenas y el Estado mexicano». Tesis de doctorado. UAMI, México.

Ferrajoli, Luigi, 2002, Derechos y garantías. Ley del más débil, 3. a edición. Trotta, Madrid. (Colección Estructuras y procesos. Serie Derecho.)

Fetscher, Irving, 1994, La tolerancia. Una pequeña virtud imprescindible para la democracia. Gedisa, México.

Florescano, Enrique, 2000, Memoria indígena, 1. a reimpresión. Taurus, México.

Gibson, Charles, Los Aztecas bajo el domino español (1519/1810), México, S. XXI 
Gil, Fernando y Ricardo Corleto, 1998-2003, La Bula Sublimis Deus de Pablo III, 1537, 2 de junio. En http://webs.advance.com.ar/pfernando/DocsIglLA/Paulo3_sublimis.htm. Pontificia Universidad Católica, Argentina.

Heuer, Uwe-Jens, y Gregor Schrimer, 1997 (mayo) a 1998 (abril), «Human rights imperialism». En Monthly Review, vol. 49, núm. 10, http://monthlyreview.org/398heuer.htm

Kelsay, John y Twiss, Sumner B. (editores), 1994, Religion and human rights. The project on religion and human rights, Nueva York.

Krotz, Esteban, 2002, La otredad cultural entre utopía y ciencia. Un estudio sobre el origen, el desarrollo y la reorientación de la antropología. UAMI-FCE, México.

Lerner, Natan, 1996, «Religious human rights under the Unites Nations». En Religious human rights in global perspective. Legal perspective, vol. 2, editado por Van der Vyver, Johan y John Witte Jr., pp. 79-134. Martinus, Nijhoff Pub., La Haya/Boston/Londres.

—, 1998, «Proselytism, change of religion and international human rights». En Emory International Law Review, núm. 2, invierno. Emory, GA, EUA.

Little, David, 1996, «Studying Religious human rights: Methodological foundation». En Religious human rights in global perspective. Legal perspective, editado por Van der Vyver, Johan y John Witte Jr., vol. 2, pp. 45-78. Martinus, Nijhoff Pub., La Haya/Boston/Londres.

López Austin, Alfredo, 2002, Breve historia de la tradición religiosa mesoamericana. IIA/UNAM, México. (Colección Textos, Serie Antropología e Historia Antigua, núm. 2.)

López Bárcenas, Francisco, Guadalupe Espinoza, et al, 2002, Los derechos indígenas y la reforma constitucional en México. 2da. ed., CeAcatl/Redes/CasaVieja/COAPI, México.

Maduro, Otto, 1980, Religión y conflicto social en América Latina. Centro de estudios ecuménicos, México.

Marcuse, Herbert, 1968, «Repressive tolerance». En A critique of pure tolerance, Paul 
Wolff et al. John Cape Ltd., Londres.

Marzal, Manuel, 1988, Sincretismo religioso iberoamericano. Pontificia Universidad Católica de Perú, Fondo Editorial, CONCTEC, Perú.

Mendieta, Fray Jerónimo, De, 1980, De Historia eclesiástica indiana, Porrúa.

Mutua, Makau Wa, 1996, «Limitation on religious rights: Problematizing religious freedom in the Africa context». En Religious human rights in global perspective. Legal perspective, editado por Van der Vyver, Johan y John Witte Jr., vol. 2, pp. 411-440. Martinus, Nijhoff Pub., La Haya/Boston/Londres.

—, 2002, Human Rights. A political and cultural critique. University of Pennsylvania Press, Filadelfia.

OIT, 1989, «Convenio $\mathrm{N}^{\mathrm{o}} 169$ Sobre Pueblos Indígenas y Tribales en Países Independientes». OIT, Oficina regional para América Latina.

Ortega Arenas, Joaquín, 1992, La Iglesia y el Estado. Claridad, México.

Reid, Ann, 1999, «Disruptions to memory in sixteenth century Mexico». En http://www.kcl.ac.uk/depsta/rel/clacs/extranet/reid/disruptions-mex.htm. Clacs，King College, Londres.

Rohr, Elizabeth, 1997, «La destrucción de los símbolos culturales indígenas. Sectas fundamentalistas, sincretismo e identidad indígena en el Ecuador». En Abya-Yala, núm. 48. Quito, Ecuador.

Sahgún, Bernardino, DE, 1956, Historia General de las cosas de la Nueva España. 4 Vol. Porrúa, México.

Santos, Boaventura de Sousa, 1991, Estado, derecho y luchas sociales. ILSA, Colombia. Soberanes, José Luis, 1999, «The new legislation on religious freedom in Mexico». En Religious freedom and evangelization en Latin America. The Challenge of religious pluralism, editado por P. Sigmund, pp. 129-138. Orbis Book, Maryknoll, Nueva York.

"The United Nation Convention of the Elimination from all forms of Racial Discrimination", entró en vigor en 1969 , en http://www.unhchr.ch/spanish/html/menu3/b/d_icerd_sp.htm

Touraine, Alain, 2000, ¿Podemos vivir juntos? FCE, México. 
Valadés, Diego y Rodrigo Gutiérrez Rivas, 2001, Derechos humanos. Memoria del IV Congreso Nacional de Derecho Constitucional III. IIJ/UNAM, México. (Serie Doctrina jurídica, núm. 64.)

—, 2002a, Problemas constitucionales del Estado de derecho. UNAM, México. (Serie Estudios jurídicos, núm. 4.)

—, 2002b, «Los derechos de los indígenas y la renovación constitucional en México». En Constitución y derechos indígenas, coordinado por Jorge Alberto González Galván, pp. 13-20. IIJ/UNAM, México. (Serie Doctrina jurídica, núm. 92.)

Valero, José A, 2002, «El otro como no-cultura y como anticultura en el discurso épico de la conquista de América». En Espéculo, año VIII, núm. 20, marzo-junio. Facultad de Ciencias de la Información, Universidad Complutense de Madrid, http://www.ucm.es/info/especulo/numero20/val_otro.html

Van der Vyver, Johan, 1996, «Introduction. Legal dimension of religious human rights: Constitutional text». En Religious human rights in global perspective. Legal perspective, editado por Van der Vyver, Johan y John Witte Jr., vol. 2, pp. IX-XLVII. Martinus, Nijhoff Pub., La Haya/Boston/Londres.

Villoro, Luis, 1999, Estado Plural. Pluralidad de culturas. Paidós/UNAM, México.

—, 2002, «El Estado nación y las autonomía indígenas». En Constitución y derechos indígenas, coordinado por Jorge Alberto González Galván, pp. 231-240. IIJ/UNAM, México. (Serie Doctrina jurídica, núm. 92.)

Witte Jr., John, 1996, «Introduction». En Religious human rights in global perspective. Religious perspective, editado por Van der Vyver, Johan y John Witte Jr., vol. 1, pp. XVII-XXXV. Martinus, Nijhoff Pub., La Haya/Boston/Londres.

Wood, James E. Jr, 1996, “An apologia for religious human rights”, en van der Vyver, Johan y John Witte, Jr (eds) Religious human rights in global perspective. Religious perspective, vol. 1, Martinus, Nijhoff Pub., The Hague/ Boston/ London, 455- 483 pp

\section{ENCICLOPEDIAS ELECTRÓNICAS}

Enciclopedia Británica, Edición Multimedia, 1999, en CD ROM.

http://www. britannica.com 
Microsoft Encarta 2000. 1993-1999 Microsoft Corporation.

\author{
Enciclopedia Hispánica, Barsa Internation Publisher, Inc., 1999 en CD ROM. \\ Enciclopedia Universal Micronet, Edición Clásica, Madrid, 2001 en CD ROM.
}

Notas

\begin{abstract}
${ }^{1}$ La invisibilización o minorización de los pueblos indígenas y tribales se ha dado también en el ámbito internacional.

${ }^{2}$ La Declaración sobre la eliminación de todas las formas de intolerancia y discriminación fundadas en la religión o las convicciones, adoptada RAG 35/55, 25 Nov. 1981; habla de dejar en paz -dejar solo- para escoger libremente cómo y en qué creer; sin embargo, debido a la correlación de fuerzas, los pueblos que fueron colonizados se encuentran en condiciones de subordinación y discriminación que hace difícil ejercer este derecho. El libro de Mutua (2002) hace una excelente argumentación para el caso de África y da elementos para las religiones indígenas en general.

${ }^{3}$ El trabajo de Esteban Krotz (2002) me parece sugerente para repensar el quehacer antropológico con el fin de observar la otredad en su diversidad y en su complejidad. Sus aportes a la disciplina contribuyen a dar otros enfoques a la concepción misma de los Derechos sobre libertad religiosa y pueblos indígenas.

${ }^{4}$ Es en la Constitución de 1857 donde se da el golpe mayor a los pueblos y comunidades indígenas con la llamada Ley Lerdo o Ley de desamortización de las corporaciones civiles y eclesiásticas; muchos también se refieren a ella como Ley de desamortización de bienes de manos muertas, misma que afectó a los bienes de la Iglesia y a los de las comunidades indígenas. En términos culturales, fue después de la revolución de 1910 cuando se construyó una ideología integracionista y se habló de la necesidad de la unidad nacional mediante el proceso de homogeneización para la creación del Estado moderno. Ello implicó, como nos dice Miguel Bartolomé, la represión de la pluralidad cultural, la castellanización forzada, el establecimiento en el ámbito nacional de un proyecto de aculturación que representaba el símbolo de la identidad nacional (1996: 5).

${ }^{5}$ Ferrajoli nos dice que las líneas jurídicas que se han seguido para fundamentar la igualdad solo han logrado fomentar la desigualdad al pretender un sujeto abstracto no vinculado con grupos y culturas. Utilizando el ejemplo de las mujeres como un caso de sectores que quedan fuera de esa igualdad o de la definición de lo igual: «... son "iguales" entre sí en cuanto identificados únicamente con los sujetos varones, ciudadanos, blancos, alfabetizados y propietarios» (2002: 77). Bajo esta perspectiva podemos observar el Estado y la sociedad mexicanos.

${ }^{6}$ La Espada y la Cruz ya estaban íntimamente relacionadas, como lo podemos constar en las cruzadas contra los protestantes y contra los infieles del Nuevo Mundo; era un honor morir por la cristiandad. Esto significó la justificación de la guerra y la superioridad cristiana sobre cualquier otra religión y el no respeto por otras religiones. Por lo que se refiere al caso de África con respecto a los procesos de conversión al cristianismo e islamismo, Mutua nos dice que, al considerarse las expresiones religiosas nativas como inferiores, los nativos eran vistos como no completamente humanos, y por ende podían legalmente ser esclavizados, pues ambas religiones universalistas argumentaban la cuasi-humanidad, la característica bestial sub-humana (1996: 425426) -argumentos que también encontramos en el Nuevo Mundo con respecto a los originarios de esas tierras. ${ }^{7}$ La evangelización de América abrió la discusión no solo sobre la humanidad o no de los indios sino también sobre el derecho que se arrogó la Iglesia católica de conceder la posesión y derechos sobre las tierras descubiertas, violentando a los grupos originarios de esos lugares. Asimismo la obligación de cristianizarlos, de esta manera justificó la posesión y el hecho de hacer la guerra para lograr la extirpación del príncipe de las tinieblas. Por ello, la guerra era un instrumento para instaurar el Reino de Dios. Se la justificaba en dos sentidos: por una lado, se hablaba de estas tierras y su moradores como la 13. ${ }^{a}$ tribu de Israel, y por lo tanto era menester recuperarla de la manos de Satanás; por otro lado, se la consideraba como la oportunidad de llevar a cabo la utopía de Iglesia indiana, en la cual se comparaba a Tenochtitlán con Jerusalén, pero se decía que tenía que ser destruida primero y después vuelta a construir. Véanse Reid (1999), Fray Gerónimo de
\end{abstract}


Mendieta. Historia eclesiástica indiana; Bernardino de Sahagún. Historia General de las cosas de la Nueva España.

${ }^{8}$ Para Ann Reid (1999), la disrupción de la memoria se llevó a cabo fundamentalmente en el siglo XVI, debido a que los elementos básicos de la memoria indígena, los elementos de transmisión del pasado y presente, habían sufrido un colapso importante a través de la destrucción de templos, ídolos, quema de códices, cambio en el uso de espacio ritual y público -ahora para uso de la Inquisición-, y los cantos y los rituales, así como la obra pictórica, donde se narraba la historia presente y pasada. Se rompió con los ciclos de vida individual y colectiva.

${ }^{9}$ El proceso de evangelización masiva llevado a cabo por los franciscanos en los primeros años del siglo XVI no fue la forma idónea de garantizar una evangelización real. Años después se recurrió a formas más selectivas y eficaces de evangelizar, debido a la reiterada continuidad de las prácticas propias, consideradas idolátricas. No obstante la labor de evangelización y celo del Santo Oficio para erradicar las idolatrías, estas se han conservado hasta nuestros días. Se ha conservado un contenido o sustrato mesoamericano, como nos lo muestran varios autores: Gibson, Charles, Los Aztecas bajo el domino español (1519/1810), México, S. XXI; López Austin, Cuerpo humano e ideología. Las concepciones de los antiguas nahuas, 2 v., IIA- UNAM; Los mitos del tlacuache. Caminos de la mitología mesoamericana, IIA / UNAM, 2002; Florescano. op. cit. 2000; Carmagnani. 1993, El regreso de los dioses. El proceso de reconstrucción de la identidad étnica en Oaxaca,(Siglo XVII y XVIII); Bartolomé 1997, 1999, 2003.

${ }^{10}$ Véanse los trabajos en general de Alfredo López Austin y Miguel Bartolomé, junto con los de Gibson, entre otros.

${ }^{11}$ En pleno siglo XXI debemos igualmente incluir a grupos no cristianos que también están evangelizando a población indígena, como los islámicos o derivaciones de éstos, entre otros.

${ }^{12}$ Se dispuso una convocatoria pública que hizo el Congreso local para discutir una iniciativa de ley que penalizaría las expulsiones en general de miembros de las comunidades por parte del mismo pueblo. Infinidad de propaganda de grupos evangélicos hace referencia a lo satánico, a la brujería y al mal que hay en las costumbres indígenas. Véase: http://hispanos.imb.org/story.asp?StoryID=2506\&LanguageID=5847.

${ }^{13}$ Por ejemplo, John Locke aceptaba la libertad religiosa pero no para los católicos.

${ }^{14}$ Se publicó la segunda reforma en materia indígena el 14 de agosto de 2001 en el Diario Oficial de la Federación. Un decreto que adicionó a la Constitución Política de los Estados Unidos Mexicanos, un segundo y tercer párrafos al artículo primero, reformó su artículo $2^{\circ}$, derogó el primer párrafo del artículo $4^{\circ}$, adicionó un sexto párrafo al artículo 18 y otro a la fracción tercera del artículo 115 . Puede consultarse entre otros: López Bárcenas et al. 2002, Los derechos indígenas y la reforma constitucional en México; artículos periodísticos, revistas especializadas y el mismo Diario Oficial de la Federación. La primera reforma constitucional en materia indígena fue en 1992, a través de una adición al artículo 4to Constitucional, derogado posteriormente, como ya mencioné.

${ }^{15}$ No significó en realidad una libertad religiosa sino que ordenó las posibilidades religiosas en cada estado y estableció las previsiones, tanto para los príncipes como para los súbditos. Bajo este nuevo principio «cuis regio, eius religio», los príncipes seculares tenían el derecho de dictar la religión de su reino, lo que implicaba, o al menos ese era el deseo, garantizar a sus súbditos una religiosidad homogénea (Fabre 2005: 25, 83 y 85$)$.

${ }^{16}$ Acción que ha sido la más frecuente en la construcción de los Estados nacionales que no reconocen la diversidad cultural y pretenden construir una identidad nacional borrando las culturas preexistentes, como en el caso de América Latina, donde los Estados nacionales han surgido como Estados unitarios homogeneizantes a partir de una cultura dominante que pretende borrar la existencia de las culturas preexistentes. El Estado establece una relación con estas culturas desde una perspectiva política de minorías; estatuto legal que configura nacional e internacionalmente relaciones muy diferenciadas.

${ }^{17}$ El marco legal nacional se revisará posteriormente.

${ }^{18}$ Para mayor profundidad en el tema sobre la relación entre los Estados, los instrumentos internacionales y nacionales sobre derechos humanos, así como las reformas en materia religiosa y pueblos indígenas en México, véase mi tesis doctoral: Fabre 2005.

${ }^{19}$ Obligatorio, mandatorio, que es preceptivo, que expresa un mandato positivo y no un permiso. 
${ }^{20}$ Consideremos que desde la década de los 60 se discute sobre la pertinencia o no de hacer una ley obligatoria, y que tomó más de 20 años la elaboración de la Declaración, a partir de la DUDH en 1948. Un análisis de las disputas y controversias sobre los derechos religiosos, de lo que fue el proyecto para la declaración y de lo que es en la actualidad el proyecto de pacto, se puede ver en el trabajo de Van der Vyver (1996) y en "The United Nation Convention of the Elimination from all forms of Racial Discrimination", entró en vigor en 1969, en http://www.unhchr.ch/spanish/html/menu3/b/d_icerd_sp.htm entró en vigor en 1969, en http://www.unhchr.ch/spanish/html/menu3/b/d_icerd_sp.htm

${ }^{21}$ Además de la depreciación de lo religioso que veremos más adelante.

22 En el siglo XX se dieron numerosos cambios constitucionales que modificaron las relaciones entre el Estado y las religiones, ahora llamadas «asociaciones religiosas».

${ }^{23}$ Esto puede ser al contrario: que quien incite sea el grupo religioso, atentando contra la libertad religiosa y libertad de conciencia de otros, como es el caso de los procesos de conversión a través de las estrategias.

${ }^{24}$ Para mayor información sobre cómo han sido ubicados los pueblos indígenas en la correlación de fuerzas internacional y nacionalmente, véase mi tesis doctoral: Fabre 2005, capítulos 2, 4 y 5.

${ }^{25}$ Recientemente ha sido aprobado por la Asamblea General de las Naciones Unidas (UN), la Declaración Universal de Derechos de los Pueblos Indígenas (DPI), 13 de septiembre de 2007.

${ }^{26}$ Se ha vuelto sin lugar a duda un axioma generalizado, independientemente de las dificultades que tiene su instrumentación y colisión jurídico-religiosa con algunas naciones, como son los países musulmanes, con el Shari’a. Más información al respecto en Wood Jr. 1996.

${ }^{27}$ Minorías de todo tipo, asociaciones étnicas o culturales, etc., lo cual no implica el ejercicio pleno de derechos, sino que los reclamos de estos grupos son palpables, así como también los conflictos y las tensiones, creándose evidencias cada vez más visibles de la complejidad que existe en la contraposición de intereses, más que realmente garantizar los derechos humanos.

${ }^{28}$ Primera Generación: derechos inalienables de todo individuo; es la generación de los derechos civiles y políticos. Se reconocen estos derechos porque toman la forma de libertades más que de derechos, debido a que están más bien en favor de la abstención que de la intervención de los gobiernos para garantizar la dignidad y libertad humana, contenidos en la DUDH en los artículos 2 a 21. Segunda Generación: derechos económicos, sociales y culturales, que se ubican más en la perspectiva de derechos en los cuales es necesaria la intervención de los Estados para garantizar la participación equitativa en la producción y distribución de los bienes; incluye el derecho al trabajo, a una vida digna. Surgen como respuesta a las desigualdades generadas por el mundo capitalista; se conocen estos derechos como generados por los países socialistas y comunistas una respuesta más social y económica para garantizar el pleno desarrollo-; básicamente son reclamos para demandar igualdad social: estos derechos se encuentran en el PIDES. Tercera Generación: usualmente no se encuentran plasmados en tratados internacionales; apoyan a reclamos de grupos sobre tierra, prácticas culturales, el uso de su lengua y la autodeterminación. Generalmente se encuentran entre estos grupos pueblos indígenas y minorías étnicas. Se conocen como los derechos a la solidaridad y están interconectados con los dos primeros. Son básicamente seis los derechos que se demandan; los tres primeros están relacionados con los nacionalismos del tercer mundo y sus demandas de una distribución global del poder, de la riqueza y del derecho a la autodeterminación política, económica, social y cultural; derecho al desarrollo económico y social; derecho a participar en los beneficios «de la herencia común de la humanidad -compartir los recursos de la tierra-, espacio, científicos, técnicos)»; derecho a la información, derecho a la paz, a un ambiente sano y a la ayuda humanitaria en desastres. Estos son derechos colectivos, aunque cada una de estas demandas manifiesta una dimensión individual y colectiva de todos los países y todas las personas. Son todavía más bien una aspiración que una realidad legal, ya que mantienen un estatus ambiguo en las normas internacionales de los derechos humanos. (http//www. EncyclopaediaBritannica, «Human Rights», 2000).

${ }^{29}$ Durkham hace un análisis sobre las relaciones entre Estado y libertad religiosa, a través de observar la estabilidad política, la naturaleza e historia de las relaciones entre E/I, y que el grado de pluralidad religiosa existe entre otros aspectos, como la tolerancia e intolerancia religiosa, que muestra la gran variedad de percepciones y valores involucrados en las relaciones entre Estado y sistemas religiosos (1996: 1-44).

${ }^{30}$ E internacionalmente también, como ya se vio.

31 Existen los Convenios Internacionales sobre Derechos Políticos y Civiles (PIDCP) y el Convenio Internacional sobre Derechos Económicos, Sociales y Culturales (PIDESC); ambos fueron ratificados al 
mismo tiempo y entraron en vigor el 3 de enero de 1976. Estos pactos contienen referencias a la religión; se derivan del artículo 18 de la Declaración Universal de los Derechos Humanos, pero no hablan de derechos religiosos de los pueblos indígenas ni avanzan sobre lo dicho en el artículo 18 de la DUDH, por lo que solo queda la DEIDRC como referente importante.

${ }_{32}$ Como lo llama Durkham (1996) Véase Fabre 2005, capítulos 1 y 2, en donde se estudian estas diferencias.

${ }^{33}$ Los trabajos de Mutua 1996 y 2002 son interesantes para el caso de África, el cual es pertinente también para América Latina. Con respecto a las conversiones, las Iglesias ortodoxas cristianas en Oriente hacen un reclamo sobre el proselitismo beligerante que viene del Occidente cristiano.

${ }^{34}$ Existen algunos cambios, por ejemplo, se tiene una Ley administrativa sobre violencia intrafamiliar, aunque no en todos los estados; y una Ley del menor, en igual caso que el anterior. Para los enfermos de sida no hay protección ni garantía de medicamento.

35 No solo el concepto sino también declaraciones a través de convenios y legislaciones internacionales y nacionales sobre los derechos religiosos.

${ }^{36}$ Rodrigo Borja nos dice: «Lo acertado, desde el punto de vista técnico-jurídico, es considerar al Estado como una sociedad total, dentro de la cual funcionan diversas sociedades menores encargadas de la consecución de finalidades específicas» (op. cit.: 237), «no puede haber más que un orden de relaciones entre las Iglesias de los diferentes cultos religiosos y el Estado: el de absoluta y total sujeción jurídica de aquéllas a éste. Es decir, un orden de relaciones similar al que existe entre el Estado y las sociedades especiales de carácter científico, artístico, cultural, deportivo, social o de cualquier otra índole que funciona dentro de su ámbito territorial ... [P]ara efectos de determinar la naturaleza de sus relaciones con el Estado bajo cuyo ordenamiento legal viven» (op. cit.: 236). La relación jurídica que aquí se expresa es una de las muchas posibilidades jurídicas entre el Estado y los sistemas religiosos, válida para el caso mexicano, entre otros.

37 Esta visión del lugar que ocupan los sistemas religiosos es una perspectiva técnico-jurídica que no contempla la incidencia sociocultural en términos de dotar de una visión de mundo y prácticas sociales concretas.

${ }^{38}$ Como ejemplo, los casos de China, Rusia y Cuba, donde existía una clara posición estatal en contra de los sistemas religiosos, o el caso contrario, Irán, donde el Estado es un Estado religioso en el que existe una relación estrecha entre religión, cultura y gobierno.

${ }^{39}$ Vale la pena decir que la secularización, como parte de un proceso histórico que muestra la separación de poderes entre el ámbito religioso y el político-social, es importante, ya que permite observar la independencia e interdependencia de ambos poderes y los procesos subsecuentes derivados de dicha separación.

${ }^{40}$ Las grandes tradiciones religiosas, dice Witte Jr., no hicieron declaraciones formales sobre tolerancia religiosa y libertad religiosa hasta el siglo XX; fueron la Iglesia católica, hasta el Concilio Vaticano II (19621965), y algunos judíos y organizaciones ecuménicas quienes aportaron significativamente a la construcción del concepto moderno de los derechos religiosos. Witte Jr. agrega acertadamente lo siguiente: «The general theological principles set out in their post-War manifestoes early endorsement of religious rights; provisions in early international and constitutional texts were not followed by specific lobbying and litigation efforts. Whatever mainline religious communities were content with their own condition, or intent to turn the other cheek or look the other way in the face of religious rights abuses, their relative silence did considerable harm to the cause of religious rights and liberties» (1996: XXXII). Actualmente, a pesar de la legislación internacional y nacional, seguimos observando un sinnúmero de conflictos religiosos, violación y represión religiosa.

${ }^{41}$ Otto Maduro en su texto nos muestra esta relación de autonomía y de autogestión de los sistemas religiosos y la correlación de fuerzas que se establece entre la sociedad y los sistemas religiosos al ubicar la religión y el conflicto social (Maduro 1980)

${ }^{42}$ Las manifestaciones políticas y de poder de las instituciones religiosas son evidentes y muestran claramente las tensiones constantes entre el poder del Estado y el de las Iglesias, así como el de no otorgar a los individuos libertad religiosa como una forma de control y de supeditación. Witte Jr. hace referencias específicas a esta idea de no hacer patente la adición a la Declaración sobre los derechos religiosos individuales sino hasta el Concilio Vaticano II. Aunque no niega las claras expresiones de algunas religiones sobre la creación de los derechos individuales y libertad religiosa. Pero como manifestación clara y completa, hasta 1962-65. (Witte Jr. op. cit., pp. XXX-XXXV). En el trabajo de James Wood Jr. se encuentran las 
referencias sobre la Declaración Universal de los Derechos Humanos y el artículo 18 referido específicamente a la libertad religiosa (Wood Jr. op. cit., p. 478).

${ }^{43}$ Wood Jr. nos hace una análisis de la trayectoria del concepto de derechos religiosos en los sistemas religiosos, especialmente del cristianismo en la Edad Moderna hasta llegar a las declaraciones de la Iglesia católica en el Concilio Vaticano II, donde explícitamente se cambia de discurso sobre los derechos religiosos individuales desde una perspectiva cristiana, apegada a sus fundamentos básicos (Wood Jr. ibid, pp. 476-478).

${ }^{44} \mathrm{Al}$ respecto están los trabajos de An-Na im, de Artz y Villa-Vicencio, los cuales muestran y examinan la diversidad cultural y los derechos universales, introduciendo una reflexión sobre el multiculturalismo y los derechos religiosos, en el libro editado por Van der Vyver y Witte Jr. 1996.

${ }^{45}$ Investigación que realicé en Oaxaca en 1992, revisión de expedientes religiosos, encuestas y entrevistas. Entre algunos de los efectos de estos conflictos están la quema de casas, sanciones económicas, restricciones para sus prácticas religiosas e incluso expulsiones de la comunidad. Así como la violación de los acuerdos comunitarios por parte de misioneros, violentar la privacidad de aquellas personas que no desean estar sujetas al proselitismo, etc. Todo lo anterior también es recurrente en otros estados del país como Chiapas, Hidalgo, Nayarit, Jalisco, Puebla, Veracruz, etc., donde la problemática es similar y la constante violencia continúa aún hoy; también es cierto que hay situaciones de convivencia pacífica, como he podido constatar.

${ }^{46}$ Considero importante el desarrollo y la consolidación de un área como la antropología jurídica, y más aún, la creación y el fortalecimiento, por ahora, del peritaje antropológico. Así como capacitación a los servidores públicos en materia de libertad religiosa y derechos de los pueblos indígenas, entre otros temas importantes, para encontrar nuevas formas de negociar y dirimir conflictos religiosos.

${ }^{47}$ Finalmente, como ya mencioné, en septiembre de 2007 se aprueba la Declaración de las Naciones Unidas sobre los Derechos de los Pueblos Indígenas, que es ya un principio fundamental para su reconocimiento político en el ámbito internacional, lo que permitirá mayor incidencia de este ámbito en la violación a derechos humanos consignados en la Declaración sobre pueblos indígenas.

${ }^{48}$ Esto requiere un trabajo profundo que permita la reflexión sobre los conceptos y las disposiciones sociales y jurídicas en los cuales descansan las propuestas de solución de conflicto. En el trabajo de Fabre (2005) se desarrollan algunos aspectos de esta problemática, que requiere de un espacio para otro artículo.

${ }^{49}$ Valadés nos dice que la tolerancia tiende a mediar entre las relaciones asimétricas y la concentración de poder en el Estado a través de las constituciones; cuando esto no ocurre surgen relaciones asimétricas y concentración de poder (2002a, pp. 81-106).

${ }^{50}$ Los conceptos de derechos humanos requieren forzosamente de insertarse en grupos, comunidades, pueblos y naciones concretas, por lo cual no es posible hacer tabla rasa, generalizarlos, como conceptos únicos y absolutos. Los trabajos recopilados en Va n der Vyver (1996) en Bloom, Martin et al. (1996), y en Caney y Jones (2001), son un buen ejemplo de la complejidad de los derechos humanos y la diversidad global.

Fecha de recepción: 04 de junio de 2007

Fecha de aceptación: 20 de septiembre de 2007 